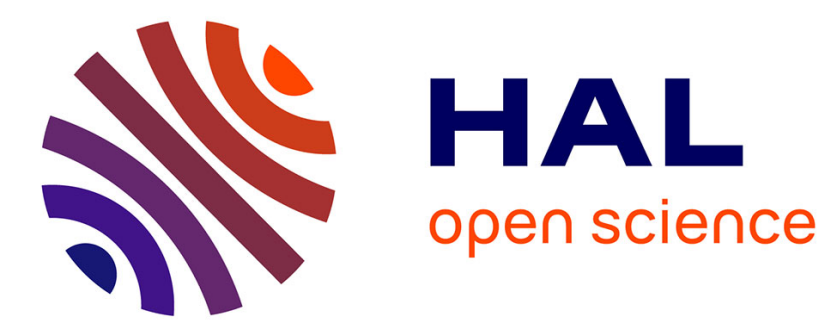

\title{
Perminvar-Like Behaviour in some Hexagonal Ferrites
}

\author{
Z. Simsa, R. Gerber, V. Lewis, V. Brabers
}

\section{To cite this version:}

Z. Simsa, R. Gerber, V. Lewis, V. Brabers. Perminvar-Like Behaviour in some Hexagonal Ferrites. Journal de Physique IV Proceedings, 1997, 07 (C1), pp.C1-197-C1-198. 10.1051/jp4:1997173 . jpa00255120

\section{HAL Id: jpa-00255120 \\ https://hal.science/jpa-00255120}

Submitted on 1 Jan 1997

HAL is a multi-disciplinary open access archive for the deposit and dissemination of scientific research documents, whether they are published or not. The documents may come from teaching and research institutions in France or abroad, or from public or private research centers.
L'archive ouverte pluridisciplinaire HAL, est destinée au dépôt et à la diffusion de documents scientifiques de niveau recherche, publiés ou non, émanant des établissements d'enseignement et de recherche français ou étrangers, des laboratoires publics ou privés. 


\title{
Perminvar-Like Behaviour in some Hexagonal Ferrites
}

\author{
Z. Simsa, R. Gerber*, V. Lewis* and V.A.M. Brabers** \\ Institute of Physics ASCR, Cukrovarnická 10, 16200 Praha 6, Czech Republic \\ * University of Salford, M5 4WT Salford, U.K. \\ ** University of Technology, 5600 Eindhoven, The Netherlands
}

\begin{abstract}
A novel, perminvar-like behaviour of the magnetization curves in the hard direction of titanium containing bulk and thin film barium hexagonal ferrites was observed at low temperatures. The DC moments and AC susceptibilities in the $1-1000 \mathrm{~Hz}$ frequency range were measured by VSM and SQUID magnetometers in the easy and hard magnetic directions at temperatures from 5 to $300 \mathrm{~K}$. The perminvar-like effects were explained on the basis of the reorientation of $\mathrm{Fe}^{2+}-\mathrm{Ti}^{4+}$ pairs in octahedral $12 \mathrm{k}$ sites of the hexagonal lattice.
\end{abstract}

\section{INTRODUCTION}

Cobalt and titanium substituted barium hexaferrites are widely used as device materials in recording and microwave applications. Although the four valent titanium is nonmagnetic its presence affects some other magnetic ions and modifies the magnetic behaviour of the substance. In such a way titanium substituted magnetites (ulvöspinels) assume at low temperatures very large magnetostriction and magnetic ánisotropy leading to nonreciprocal and time dependent minority hysteresis loops [1-2]. As we encountered indications of similar behaviour of magnetization in highly Co- and Ti-substituted hexagonal platelets and thin films it appeared desirable to make a more detailed study of the phenomena.

\section{EXPERIMENT}

Single crystal samples with compositions of $\mathrm{BaFe}_{12} \mathrm{O}_{19}$ (denoted as $\mathrm{BaM}$ ), $\mathrm{BaTiFe}_{11} \mathrm{O}_{19}(\mathrm{BaTi}), \mathrm{BaTi}_{0.2} \mathrm{Co}_{0.2} \mathrm{Fe}_{11.6} \mathrm{O}_{19}\left(\mathrm{BaCo}_{2}\right.$ ) and $\mathrm{BaTi}_{0.8} \mathrm{Co}_{0.8} \mathrm{Fe}_{10.4} \mathrm{O}_{19}(\mathrm{BaCo8})$ were grown by an arc-image floating-zone method. After the growth process was completed, the samples were additionally heat-treated and slowly cooled in controlled atmospheres to improve their oxygen homogeneity and mechanical properties. Thin films of the Co- and $\mathrm{Ti}$-substituted barium hexaferrites were prepared by laser ablation deposition onto sapphire substrates. More details about the sample preparation, optical and magneto-optical properties of both bulk and thin film samples were reported in $[3,4]$. After the measurements some samples were reduced by annealing at $800^{\circ} \mathrm{C}$ in nitrogen atmosphere to increase the divalent iron content.

The DC magnetizations (magnetic moments) were measured in the easy and hard magnetic directions at temperatures from 5 to $300 \mathrm{~K}$ either by means of the Oxford Instruments model VSM operating up to $12 \mathrm{~T}$ or by the Quantum Design model MPMS-5S SQUID magnetometer (up to $5 \mathrm{~T}$ ). The AC susceptibilitiesat frequencies of 1 to $1000 \mathrm{~Hz}$ and $0.0003 \mathrm{~T}$ drive fields were measured in the hard samples' directions at external dc applied fields up to $2 \mathrm{~T}$ by the AC option of MPMS-5S.

The magnetizations along the easy hexagonal c-axis of all samples display regular hysteresis loops reaching saturation at applied fields of about $0.5 \mathrm{~T}$. The hard direction magnetizations (perpendicular to c-axis) increase linearly up to about 0.5 . 1.6 $\mathrm{T}$ depending on the sample composition.

Minority hysteresis loops were observed for samples with a high content of titanium, ie. $\mathrm{BaTiFe}_{11} \mathrm{O}_{19}$ (bulk) and $\mathrm{BaTi}_{0.8} \mathrm{Co}_{0.8} \mathrm{Fe}_{10.4} \mathrm{O}_{19}$ (bulk and thin film), when measured below room temperature in the magnetic hard direction and parallel to the direction of the crystal growth, see Fig. 1 a). Similar but less pronounced effects were found in the hard direction of both thin film samples and bulk single crystals perpendicular to their growth direction. The magnitudes of these minority hysteresis loops diminish if the sweep speed of the applied field decreases as demonstrated in the inset of Fig. 1 a). The time changes of the magnetic moments were completed within 3 minutes after the application of the magnetic field anywhere in the "hysteresis part" of the magnetization curves.

The AC susceptibilities of BaTi and $\mathrm{BaC} 8$ samples display also a hysteretic behaviour within the same range of the applied fields as may be seen in Fig. 1 b). The magnitudes of the hysteresis parts of the AC susceptibilities decrease with increasing frequency as is indicated in the inset of the figure. The largest effects were found at temperatures between 20 and $60 \mathrm{~K}$ depending on the thermal history of the samples. No hysteresis effects with ac or dc curves were observed for the BaM and $\mathrm{BaCo} 2$ samples either in as grown or in the oxygen reduced state. 


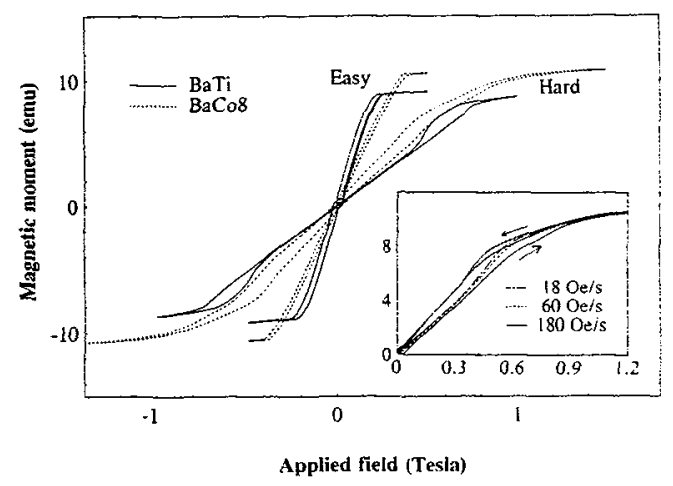

a)

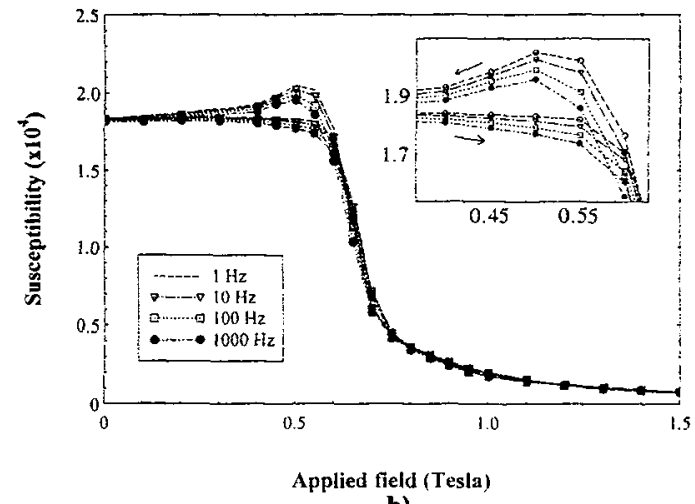

b)

Figure 1: a) The easy and hard direction bysteresis loops of $\mathrm{BaTiFe}_{11} \mathrm{O}_{19}$ and $\mathrm{BaTi}_{0.8} \mathrm{Co}_{0.8} \mathrm{Fe}_{10.4} \mathrm{O}_{19}$ bulk samples at $5 \mathrm{~K}$. The inset shows the first quadrant hysteresis curves of the $\mathrm{BaCo} 8$ sample measured at hard direction and at various speeds of the field sweep. Similar but less pronounced behaviour was also observed for the $\mathrm{BaTi}_{0.8} \mathrm{Co}_{0.9} \mathrm{Fe}_{10.3} \mathrm{O}_{19}$ film.

b) The applied field dependence of the real part of $\mathrm{AC}$ susceptibilities of the $\mathrm{BaTiFe}_{11} \mathrm{O}_{19}$ bulk sample measured at $40 \mathrm{~K}$. The inset shows a magnified section of the knee on the field dependence of the susceptibility.

\section{DISCUSSION}

With the exception of small closure domains near the sample surface, the prevailing domain structure of hexaferrites with the magnetically easy c-axis may be represented by stripe (plate) domains, separated by $180^{\circ}$ Bloch walls. When the samples are cooled down to low temperatures microscopic processes occur (electron and ion diffusion, reorientation of cation pairs etc.) which result in an additional stabilization of the walls configuration. On applying a magnetic field perpendicularly to the easy axis the domain magnetization starts to rotate into the field direction. The domain walls begin to undulate or form a zig-zag structure [5] and at each applied field value their configurations tend to stabilize at time intervals corresponding to the relaxation of the microscopic processes. After the technical saturation is reached all domain magnetizations are aligned in the applied field direction and domain walls disappear. A certain distribution of microscopic species is stabilized that corresponds to the minimum of free energy at saturated state. When the applied field is decreased this stabilized configuration prevents the nucleation of domains until the driving force and the time lap are sufficiently large to destroy it. This mechanism explains the irreversible parts of the hysteresis loops and susceptibility dependences near $0.5 \mathrm{~T}$.

The most likely relaxing species are in our opinion the $\mathrm{Fe}^{2+}-\mathrm{Ti}^{4+}$ pairs, which are also responsible for similar effects in titanomagnetites [1-2]. A simpler idea of the $\mathrm{Fe}^{2+}-\mathrm{Fe}^{3+}$ pairs cannot explain the observed phenomena since the reduction of BaM sample, leading to the creation of such iron pairs, does not bring about the appearance of the observed hysteresis effects. The temperature region where the anomalies are observed is also in agreement with the expected relaxation processes of $\mathrm{Fe}^{2+}-\mathrm{Ti}^{4+}$ pairs.

\section{References}

[1] Y. Ishikawa, S. Sato and Y. Syono, J. Phys. Soc. Japan 31 (1971) 452-460.

[2] X. Li, V.A.M. Brabers and F.R. de Boer, "High-field magnetization and cation distribution of titanomagnetites", Ferrites, Proceedings of ICF6, Tokyo 1992, T.Yamaguchi and M. Abe Eds. (JSPPM, Tokyo 1992) pp. 674-677.

[3] Z. Šimša, L. Štichauer, V.A.M. Brabers, paper No. TP.2 presented at MORIS'96, J. Magn. Soc. Japan, to be published.

[4] Z.Šimša, R.Gerber, T.Reid, R.Tesar̆, R.Atkinson and P.Papakonstantinou, "Optical absorption and Faraday rotation of barium hexaferrite films prepared by laser ablation deposition", to be published.

[5] J. Kaczér and R. Gemperle, Czech. J. Phys. B11 (1961) 157-170. 